\title{
The role of chemical admixtures in the formation of the structure of cement stone
}

\author{
Viktor Sopov ${ }^{1, *}$, Lidiya Pershina $^{1}$, Larisa Butskaya $^{1}$, Ekaterina Latorets $^{1}$, and \\ Olga Makarenko \\ ${ }^{1}$ Kharkiv National University of Civil Engineering and Architecture, Department of Physical and \\ Chemical Mechanics and Technologies of Building Materials and Products, Sumska st. 40, 61002 \\ Kharkiv, Ukraine
}

\begin{abstract}
The influence of sulfates and carbonates of potassium and sodium on the character of the formation of the microstructure of cement stone was studied. The role of cations in the structure formation of cement stone is shown. The efficiency of chemical additives, hardening accelerators, was estimated from the ratio of the volumes of gel and capillary micropores. The ratio of gel and capillary pores allows to determine the efficiency coefficient of the action of chemical additives. It is shown that the potassium carbonate for Portland cement is the most effective additive for hardening in terms of microstructure modification, and potassium sulfate for slag Portland cement.
\end{abstract}

\section{Introduction}

In predicting the durability, durability of concrete, the pore structure takes the lead. Its characteristics determine the process of destruction of concrete in the structure. In the theory of calculating the durability of concrete structures, along with other factors, the leading role of the differential pore structure has been established. The determination of these characteristics is carried out experimentally or on the basis ofsemiempirical relationships. Estimating the total porosity, these dependences do not provide answers to questions related to the shape of pores, the quantitative and probabilistic distribution of pores by size.

It is known that the most numerous and responsible for the properties of concrete is the proportion of pores - capillaries. They are permeable to water and are the reason for its penetration inside the concrete of structure, contribute to the accumulation and development of cracks. The main properties of concrete depend on the characteristics of the capillary pore structure, the formation of which begins at the early stage of cement hardening.

The process of pore formation of cement stone is much more complicated than in monomineral knitting in connection with the presence of two developing and interacting structures - hydrosulfoaluminate and hydrosilicate. The main structure-forming role is played by hydrosilicates and calcium hydroxide, which constitute the bulk of the new

*Corresponding author: vsopov1959@hotmail.com 
formations of cement stone. Despite the huge morphological diversity of other hydrate neoplasms in the hardened cement stone, their effect on certain physical and mechanical properties is deterministic and can be predicted in advance. An ensemble of micropores with a corresponding distribution of their for size determines the main properties of cement stone - strength, permeability, frost resistance, etc. Changes in the pore size in the range from 2 to $100 \mathrm{~nm}$ can dramatically change the properties of the cement stone and thus allow to control the character of the structure formation at the hardening stage. One of the levers controlling the structure of cement stone is the use of chemical and mineral admixtures.

\section{Materials and methods of research}

The effect of chemical admixtures on the character of pore formation of two types of cement was studied: Portland cement PC CEM I 42.5R and slag Portland Cement II CEM II B-S $32.5 \mathrm{R}$, differing in mineral composition, slag content and, as a result, the rate of hydration and character of structure formation (Table 1).

Table 1. Cement characteristics

\begin{tabular}{|c|c|c|c|}
\hline \multicolumn{2}{|l|}{ Showing } & CEM I 42,5R & CEM III/B-S 32,5 R \\
\hline \multicolumn{2}{|c|}{ Actual Activity, MPa } & 52.0 (28 days) & 23.7 ( 7 days $)$ \\
\hline \multicolumn{2}{|c|}{ Activity with the steaming, $\mathrm{MPa}$} & 32.0 & 25.2 \\
\hline \multicolumn{2}{|c|}{$\begin{array}{l}\text { Fineness of grinding cement (passed through a } \\
\text { sieve } 008), \%\end{array}$} & 91.0 & 91.0 \\
\hline \multicolumn{2}{|c|}{$\begin{array}{c}\text { Setting time, hr-min: - start } \\
\text { - end }\end{array}$} & $\begin{array}{l}3-20 \\
4-20\end{array}$ & $\begin{array}{l}1-50 \\
7-00\end{array}$ \\
\hline \multicolumn{2}{|c|}{ In tests on river sand: normal density } & 28.0 & 28.1 \\
\hline \multicolumn{2}{|c|}{ Signs of false setting of cement } & no & no \\
\hline Mineral composition, $\%$ & $\begin{array}{c}\mathrm{C}_{3} \mathrm{~S} \\
\mathrm{C}_{2} \mathrm{~S} \\
\mathrm{C}_{3} \mathrm{~A} \\
\mathrm{C}_{4} \mathrm{AF} \\
\end{array}$ & $\begin{array}{c}57.48 \\
21.36 \\
7.57 \\
12.35 \\
\end{array}$ & $\begin{array}{c}50.0 \\
30.0 \\
3.8 \\
16.2 \\
\end{array}$ \\
\hline
\end{tabular}

To estimate the parameters of the microstructure of the cement stone (dimensions, volume and pore size distribution), the thermoporometry method was used [1]. The experimental basis of the method is differential scanning microcalorimetry. To determine the amount of free and adsorbed water in the cement stone, it is frozen in a calorimeter and phase transitions of water are recorded, the presence and intensity of which are determined by the pore size and free water content in them [2]. The relationship between the pore radius $r$ and the crystallization temperature of the pore water $T$ is expressed by an equation of the type:

$$
r=\frac{A}{T_{0}-T}+B,
$$

where $\mathrm{A}$ and $\mathrm{B}$ are constants, depending on the experimental procedure, $\mathrm{T}_{0}=273 \mathrm{~K}$. In this case, the thickness of the layer of adsorbed water is taken into account, which is 2.5

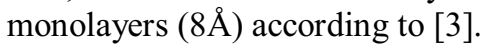

The pore volume is determined from the equation of the pore size distribution curve

$$
\frac{\Delta V}{\Delta r}=\left(a \cdot r^{2} \exp ^{-b r^{2}}\right)^{m},
$$


where $a, b$ - the coordinates of the maximum propagation curve, $m$ - width of the distribution curve at $10 \%$ of its maximum amplitude. The volume of pore space calculated according to formula (2) corresponds to the volume of the pore liquid, including free and adsorbed water.

\section{The results of research}

The hardening of all types of cement for 1 day is accompanied by the formation of a pore structure with two areas of distribution of micropores in size, characteristic for gel and capillary micropores (Fig. 1). For Portland cement, they are located in the range 2.2..22 $\mathrm{nm}$ with pore distribution maxima at 2.36, 2.45 and $14.6 \mathrm{~nm}$. For slag Portland cement, the range of distribution of micropores narrows to a range of $3.1 \ldots 6.6 \mathrm{~nm}$ with maxima at 3.4 , 3.7 and $6.3 \mathrm{~nm}$ (Fig. 1a). The volume of micropores increases by 1.3 times in comparison with portland cement (Fig. 1b) and is $0.46 \mathrm{~cm}^{3} / \mathrm{g}$. This is due to a slower binding of mixing water during hydration of the SHPC, the formation of hydrogelenite and hydrogarnets as well as calcium hydrosilicates of less basicity than with hardening portland cement. The consequence of this is a reduction in the size of capillary micropores and the formation of low-density LD C-S-H with a porosity in the range $3.1 \ldots 4.2 \mathrm{~nm}$ (Fig. 1a).

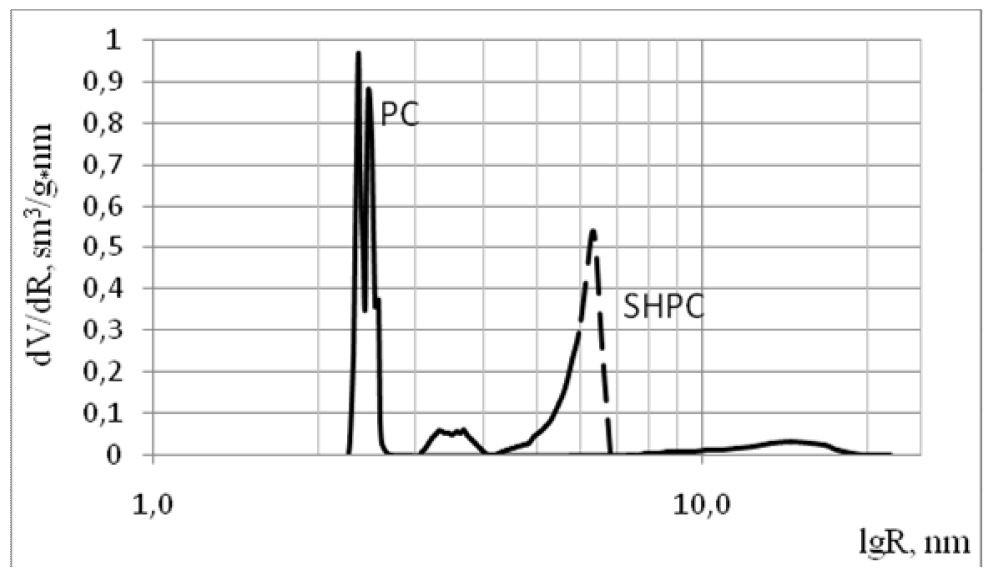

(a)

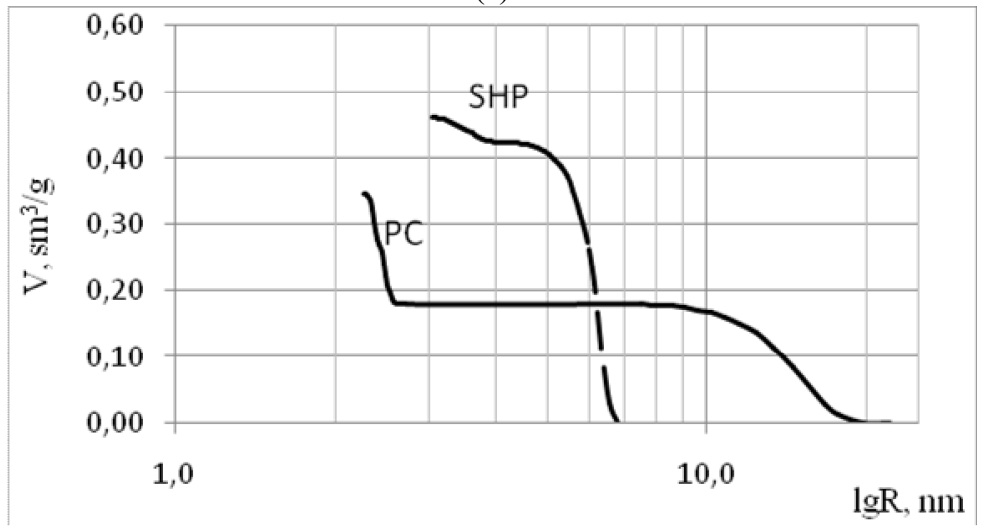

(b)

Fig. 1. Influence of cement type on microporosity of cement stone: (a) pore size distribution; (b) the total pore volume. 
The gel microporosity for the SHPC is only $7.6 \%$ of the total porosity, the analogous index for the PC is $47 \%$. Consequently, the amount of calcium hydrosilicates formed in the cement stone composition is $40 \%$ greater than that of the SHPC for the same hardening time.

The effect of hardening accelerators is based on a change in the solubility of the initial astringent and final products of its hydration due to a change in the ionic strength of the solution [4].

Admixtures that contain ions of the same name with astringents contribute to the formation of embryos of crystalline hydrate neoplasms and at low concentrations they reduce the solubility of astringent and hydrate neoplasms. As the concentration of additives increases to a certain limit, their effect increases somewhat. With an increased concentration of these additives, it is possible to react with calcium hydroxide to form double salts. As a result, the solubility of $\mathrm{Ca}(\mathrm{OH})_{2}$ and the silicate minerals of cement clinker is increased. By varying the solubility of astringent and hydrate neoplasms, it is thus possible to regulate the kinetics of cement hydration.

Admixtures that do not contain the same name with astringent ions, at low concentrations [5] accelerate hardening, and at large, the opposite effect is possible.

The most effective hardening accelerators are alkali metal salts based on $\mathrm{Na}^{+}$and $\mathrm{K}^{+}$ cations with various anions of $\mathrm{CO}_{2}{ }^{3-}, \mathrm{Cl}^{-}, \mathrm{SO}_{2}{ }^{4-}, \mathrm{S}_{2} \mathrm{O}_{2}{ }^{3-}$ and $\mathrm{CNS}^{-}$, etc.

Effect of sulphates. Sodium and potassium sulphatesare classified as admixtures of the first class [4]. The mechanism of their action is due to the reaction with calcium hydroxide, released during the hydration of cement, with the formation of a two-water gypsum:

$\mathrm{Ca}(\mathrm{OH})_{2}+\mathrm{Na}(\mathrm{K})_{2} \mathrm{SO}_{4}+\mathrm{nH}_{2} \mathrm{O}=\mathrm{CaSO}_{4} \cdot 2 \mathrm{H}_{2} \mathrm{O}+2 \mathrm{Na}(\mathrm{K}) \mathrm{OH}+\mathrm{H}_{2} \mathrm{O}$.

The resulting fine-grained gypsum reacts with cement and promotes nucleation and growth of neoplasms. Most effectively as an accelerator, sulfates show themselves on Portland cement and Pozzolan Portland cement. However, in the opinion of Yu.M. Bazhenov [6], sodium sulfate negatively affects the long-term strength of the cement stone.

In addition, $\mathrm{Na}_{2} \mathrm{SO}_{4}$ hydrolysis retains sodium $\mathrm{Na}^{+}$cations in the pore fluid, and the anionic part - $\mathrm{SO}_{4}{ }^{2-}$ is bound by alumina-containing phases. Isolation of cations of $\mathrm{Na}^{+}$leads to a change in the ionic strength of the solution, i.e. increasing the alkalinity of the medium, causing an increase in the solubility of the silicate constituents and accelerating the hardening [7]. Anions $\mathrm{SO}_{4}{ }^{2-}$ contribute to the formation of sodium-containing hydrosulfoaluminates and calcium hydrosulfoaluminoferrites [8].

The effects of sodium and potassium sulfate on the formation of microporosity during Portland cement hydration are shown in Fig. 2.

When Portland cement is solidified with $2 \% \mathrm{Na}_{2} \mathrm{SO}_{4}$, two pore distribution regions are formed: $2.5 \ldots 3.3 \mathrm{~nm}$ and $5 \ldots 16.5 \mathrm{~nm}$ with maxima at $2.7 \mathrm{~nm}$ and $10.5 \mathrm{~nm}$, respectively. The total pore volume increases by 1.2 times as compared with the sample without the admixture and is $0.41 \mathrm{~cm}^{3} / \mathrm{g}$. This character of pore formation of cement stone is associated with a change in the balance between the pores already on the first day of hardening. Sodium sulfate, accelerating the hydration of cement, promotes the rapid formation of capillary micropores in the range $5.5 \ldots 14.6 \mathrm{~nm}$ with a total volume of $0.38 \mathrm{~cm}^{3} / \mathrm{g}$ (in the control sample $0.21 \mathrm{~cm}^{3} / \mathrm{g}$ ). 


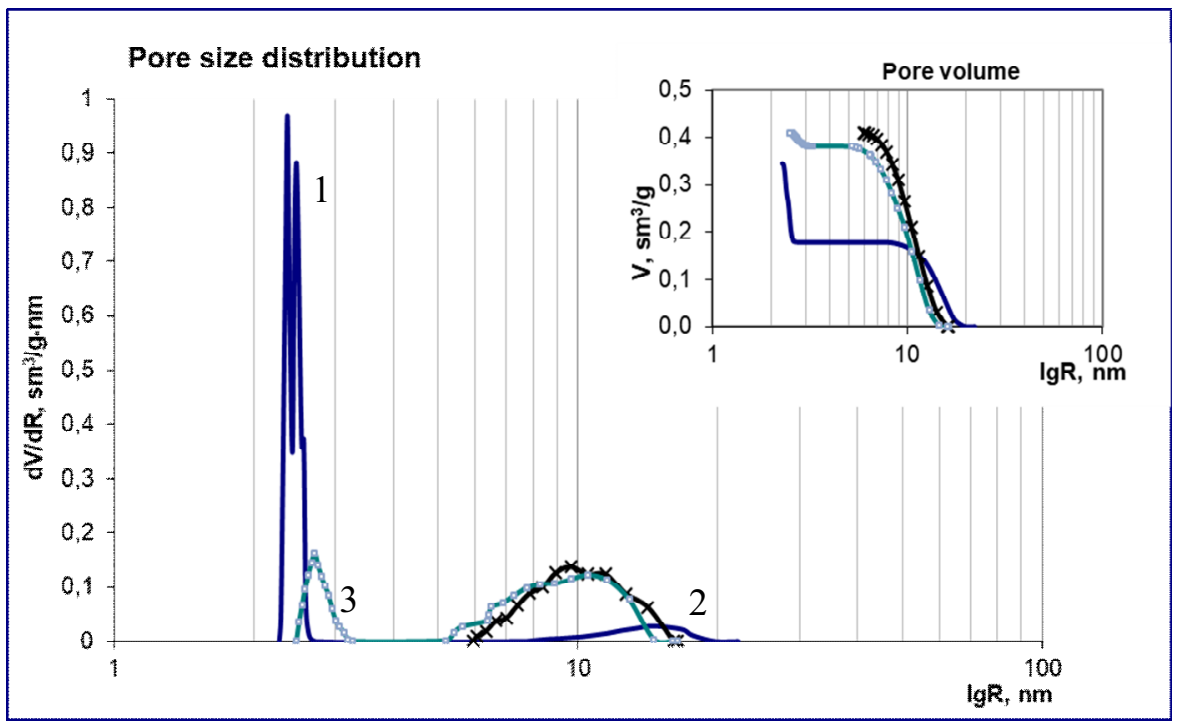

Fig. 2. Effect of sulfate admixtures on the microporosity of the cement stone $1-\mathrm{PC} ; 2-\mathrm{PC}+\mathrm{Na}_{2} \mathrm{SO}_{4}$; $3-\mathrm{PC}+\mathrm{K}_{2} \mathrm{SO}_{4}$.

When Portland cement hydrates in the presence of $2 \% \mathrm{~K}_{2} \mathrm{SO}_{4}$, one region of the pore distribution is formed in the interval $6 \ldots 14.2 \mathrm{~nm}$ with a maximum at $10.5 \mathrm{~nm}$, which corresponds to the region of the capillary pores. The total volume of micropores also increases by 1.2 times and corresponds to $0.41 \mathrm{~cm}^{3} / \mathrm{g}$. Potassium sulphate activates the formation of monosulfoaluminate and ettringite, which leads to stresses and deformations leading to a decrease in the strength of the cement stone, an increase in the volume of the solid phase, and the size of micropores.

In the process of hardening slag Portland cement without admixtures, two regions of pore size distribution are formed in the range of $2.9 \ldots 6.8 \mathrm{~nm}$ (Fig. 3). The admixture of $\mathrm{Na}_{2} \mathrm{SO}_{4}$ contributes to the formation of three regions of the distribution of pores in the range: $1.79 \ldots 17.8 \mathrm{~nm}$ with maxima at $1.9,2.4$ and $8.5 \mathrm{~nm}$. The first two areas refer to the porosity of C-S-H, and the third - to the capillary pores.

This pattern of pore size distribution confirms the formation of high-density calcium hydrosilicates - HD C-S-H $(1,75 \ldots 2,8 \mathrm{~nm})$ in the presence of sodium sulfate. Our data coincide with the results obtained by Ali Noaman Khalid Hussein [9] - two types of calcium hydrosilicates of the composition C-S-H (I) and C-S-H (II) are formed in the hardening slagPortland cement in 1 day. At 7 days, the hydrosilicates have the composition $\mathrm{C}-\mathrm{S}-\mathrm{H}$ (I) and $\mathrm{C}_{2} \mathrm{SH}(\mathrm{B})$, the hydrosilicate composition on the 14 th day is mainly CSH (II), which also indicates the presence of two types of gel microporosity related to different types of calcium hydrosilicates. 


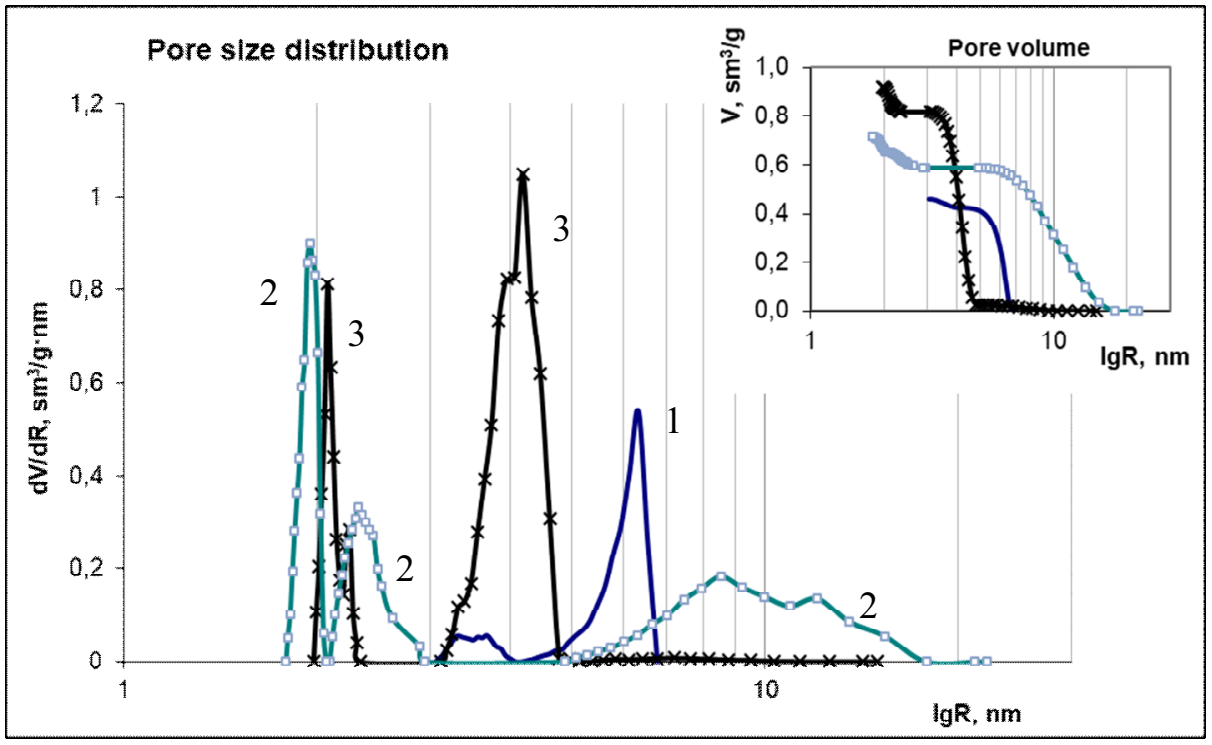

Fig. 3. Microporosity of cement stone with solidification of slag Portland cement with admixtures of sulfates: 1 - SHPC; $2-\mathrm{SHPC}+\mathrm{Na}_{2} \mathrm{SO}_{4} ; 3-\mathrm{SHPC}+\mathrm{K}_{2} \mathrm{SO}_{4}$.

When hydrating the slagPortland cement with $\mathrm{K}_{2} \mathrm{SO}_{4}$, two microporous regions are formed in the range of $2 \ldots 2.5 \mathrm{~nm}$ and $3.6 \ldots 6.6 \mathrm{~nm}$ with distribution maxima at $2.3 \mathrm{~nm}$ and $5.2 \mathrm{~nm}$. The microstructure of the slag-portland cement stone is represented mainly by the $\mathrm{C}-\mathrm{S}-\mathrm{H}$ phase with the ratio $\mathrm{C} / \mathrm{S}=1 / 1.5$. The cations $\mathrm{Na}^{+}$and $\mathrm{K}^{+}$can be embedded in such a structure, which increases the strength and resistance to chemical corrosion.

In the opinion of V.B. Ratinov in the presence of additives of sodium and potassium sulfate, new hydrate compounds - sodium-containing hydrosulfoaluminates and calcium hydrosulfoalumferrites - are formed [4]. The reaction products are formed directly in the porous space of the cement stone, filling the pores, which leads to a decrease in their size and volume. O.M. Rosenthal showed that in the presence of $\mathrm{Na}^{+}$and $\mathrm{K}^{+}$ions alone, the solubility of aluminates increases and the process of their interaction with sulfates develops in the bulk of the liquid phase of concrete with pore filling by crystalline products [10].

Differences in the effect of sulfates can be explained by the fact that for equal valence of compounds, the intensity of their effect on the ionic strength of the solution is higher for $\mathrm{Na}_{2} \mathrm{SO}_{4}$. This leads to an increase in the solubility of silicate phases of cement, acceleration of its hydration, and an earlier formation of gel microporosity.

Effect of carbonates. In the opinion of V.B. Ratinov and F.M. Ivanov carbonates of potassium and sodium react with calcium hydroxide to form $\mathrm{KOH}$, which will accumulate in the aqueous phase of the solution and contribute to a change in the composition of the pore fluid [11]. This leads to a change in the $\mathrm{pH}$ of the medium and accelerates the hydration of the cement.

Hydration of portland cement with admixture of $\mathrm{Na}_{2} \mathrm{CO}_{3}$ generates two regions of pore distribution in the intervals $2.8 \ldots 3.22 \mathrm{~nm}$ and $4.3 \ldots 14.5 \mathrm{~nm}$ with distribution maxima at 3.02 and $7.5 \mathrm{~nm}$, respectively (Fig. 4). When solidified with $\mathrm{K}_{2} \mathrm{CO}_{3}$, one region of pore distribution is formed in the range $4 \ldots 12.4 \mathrm{~nm}$ with a maximum at $7.3 \mathrm{~nm}$. The total pore volume when these admixtures are added increases 1.5 times with hydration with $\mathrm{Na}_{2} \mathrm{CO}_{3}$ and 1.3 times with $\mathrm{K}_{2} \mathrm{CO}_{3}$. 


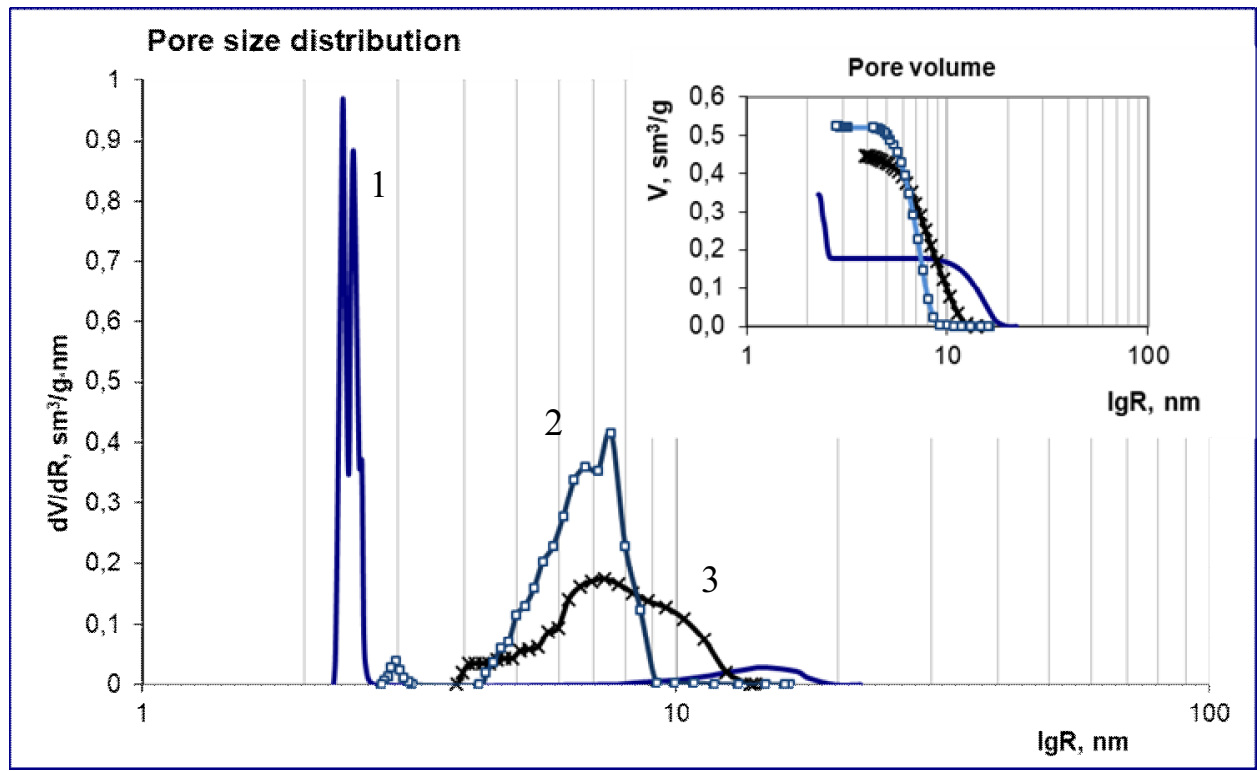

Fig. 4. Effect of carbonate admixtures on the microporosity of cement stone: $1-\mathrm{PC}$; $2-\mathrm{PC}+\mathrm{Na}_{2} \mathrm{CO}_{3} ; 3-\mathrm{PC}+\mathrm{K}_{2} \mathrm{CO}_{3}$.

The accelerating effect of carbonates on the hydration of Portland cement is due to a decrease in the size of capillary pores with simultaneous growth in their quantity. The introduction of $\mathrm{Na}_{2} \mathrm{CO}_{3}$ contributes to the formation of only a small amount of gel micropores, the total volume of which is 55 times less than that of a sample without an admixture.

Solidification of slag Portland cement in the presence of $\mathrm{K}_{2} \mathrm{CO}_{3}$ and $\mathrm{Na}_{2} \mathrm{CO}_{3}$ is accompanied by the formation of a discrete distribution of micropores in the intervals 3.4...14.5 nm and 2.24...12.4 nm, respectively (Fig.5). In slag Portland cement stone with the addition of potassium carbonate, there is practically no gel micropores. The introduction of sodium carbonate leads to the growth of gel micropores, whose volume is $10 \%$ greater than that of the control sample. But at the same time high-density calcium hydrosilicates HD C-S-H $(2.2 \ldots 3 \mathrm{~nm})$ are formed, which has a positive effect on improving the properties of cement stone and concrete. 


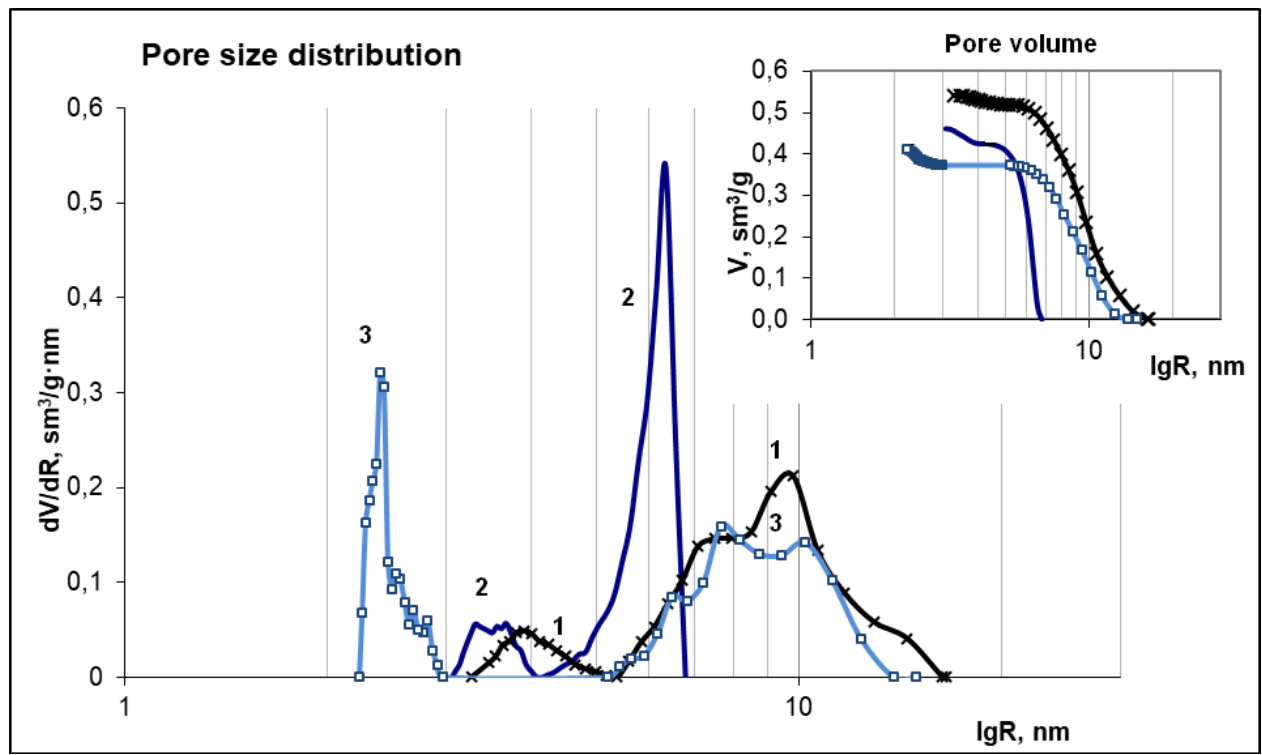

Fig. 5. Effect of carbonate admixtures on the microporosity of cement stone: 1 - SHPC; $2-\mathrm{SHPC}+\mathrm{Na}_{2} \mathrm{CO}_{3} ; 3-\mathrm{SHPC}+\mathrm{K}_{2} \mathrm{CO}_{3}$.

From these data it follows that the addition of $\mathrm{Na}_{2} \mathrm{CO}_{3}$ contributes to the early formation of gel porosity. Its formation in the opinion of V.B. Ratinov and T.I. Rosenberg [4] can be associated with the formation of gel-like substances such as sodium hydrosilicates, which provide a more dense structure, which positively affects the physical properties of concrete.

\section{Discussion of results}

Based on the obtained data on the effect of hardening accelerators in the early stages of hydration of cements and the formation of a microstructure of a cement stone, the following lyotropic series were obtained:

- for Portland cement $-\mathrm{K}_{2} \mathrm{CO}_{3}>\mathrm{K}_{2} \mathrm{SO}_{4}>\mathrm{Na}_{2} \mathrm{SO}_{4}>\mathrm{Na}_{2} \mathrm{CO}_{3}$;

- for slag Portland cement $-\mathrm{K}_{2} \mathrm{SO}_{4}>\mathrm{Na}_{2} \mathrm{SO}_{4}>\mathrm{Na}_{2} \mathrm{CO}_{3}>\mathrm{K}_{2} \mathrm{CO}_{3}$.

The ratio of gel and capillary pores allowed to determine the coefficient of efficiency of $\mathrm{K}_{\mathrm{ef}}$ in the form of the following ratio of dynamic microstructure indices [12]:

$$
R_{s f}=-\lg \left(\frac{\left|V_{\text {cap } 1}-V_{g e i 1}\right|}{V_{\text {tor1 }}} \cdot \frac{V_{\text {toto }}}{\left|V_{\text {capo }}-V_{\text {geio }}\right|}\right)
$$

where $V_{\text {gel }}$ is the volume of gel pores; $V_{\text {cap }}$ is the volume of capillary pores, $V_{\text {tot }}$ is the total volume of pores, index 1 corresponds to cement with admixtures, 0 - without admixture.

The results of the efficiency evaluation are shown in Fig. 6. 


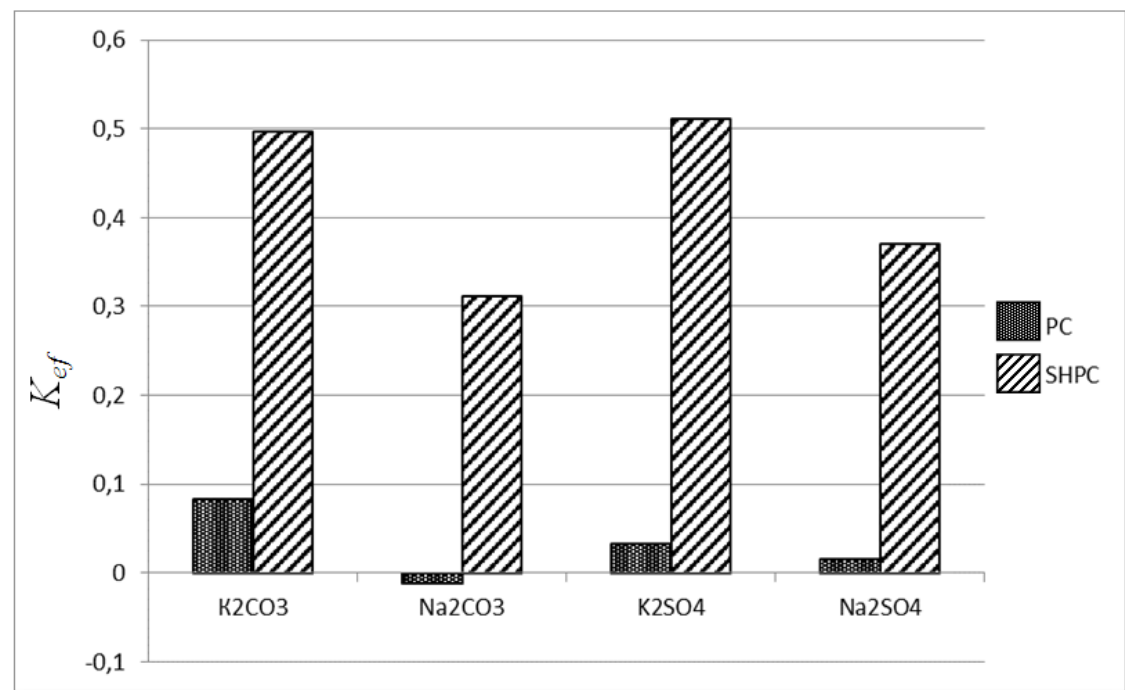

Fig. 6. Efficiency of hardening accelerators.

As can be seen from Fig. 6, for Portland cement, potassium carbonate is the most effective accelerator, and potassium sulfate for Portland slag. It should be borne in mind that the coefficient values are less than zero indicate a negative effect of the additive, at $\mathrm{K}_{\mathrm{ef}}$ $=0$ - the additive has practically no effect on the structure formation of the cement stone.

\section{Conclusions}

Studies of the influence of sulfates and carbonates of potassium and sodium showed that the character of the formation of the microstructure of the cement stone depends to a large extent on the type of cation. Evaluation of the relationship between capillary and gel pores showed that the potassium cation promotes the increase in gel porosity with a decrease in capillary porosity. It has been shown that potassium carbonate for Portland cement is the most effective additive for hardening from the point of view of microstructure modification, and potassium sulfate for slag Portland cement.

\section{References}

1 M. Brun, A. Lallimand, J.F. Quinson, and C. Eyraud, Thermochimica Acta., 21, 59-88 (1977)

2 A.V. Usherov-Marshak, V.P. Sopov, Colloid Journal, 56 (4), 600-603 (1994)

3 K.G. Krasilnikov, A.F. Tarasov, Physical and chemical research of concrete and its components, 17, 100 (1975)

4 G. Dobrolyubov, V.B. Ratinov, T.I. Rozenberg, Forecasting the durability of concrete with admixtures (Stroiizdat, Moscow, 1983)

5 V.S. Ramachandran (ed.) Concrete admixtures handbook (New Jersey, Noyes Publications, 1984)

6 Yu.M. Bazhenov, V.C. Demyanova, V.I. Kalashnikov, Modified high-quality concrete (Publishing House of Association of Construction Universities, Moscow, 2006)

7 D. Manmohan, P.K. Mehta, Cement, Concrete and Aggregates, 3, 63-67 (1981)

8 W. Kurdowski, Chemia cementy i betonu (Wyd. Naukowe PWN, Warszawa, 2010) 
9 Ali Noaman Khalid Hussein, Research hydration and hardening cement stone first condensation moisture. Thesis for the degree of candidate of technical sciences (Dnepropetrovsk, 2001)

10 O.M. Rozental, F.E. Chetin, Multilayer structural ordering in heterogeneous processes of ice formation (Publishing House of the Pedagogical Institute, Sverdlovsk, 1974)

11 V.B. Ratinov, F.M. Ivanov, Chemistry in construction (Stroyizdat, Moscow, 1969) 